\title{
AMOR, FIDELIDADE E COMPAIXÃO: "SUCATA" PARA OS PRESOS
}

Após aproximadamente vinte anos de regime militar, o Brasil passou por um processo de redemocratização ao longo da década de I980. Com a promulgação da Constituição Federal de I988, foram estabelecidas condições legais para uma ampla participação popular, além de terem sido rompidas as barreiras que limitavam o voto direto a uma parcela da sociedade. Nesse novo contexto, as agendas públicas tornaram-se mais sensíveis às reivindicações da população. Sendo a segurança um item eminentemente popular - sem deixar de ser tema prioritário também para as elites e para as camadas médias -, ela se impôs com mais peso à consideração dos atores políticos (Soares, 2003).

Salla \& Ballesteros (2008) ressaltam que a democracia, em diversos países, inclusive no Brasil, apresenta uma contradição central que se manifesta de forma bastante peculiar na área de segurança pública. Ao mesmo tempo em que se busca assegurar as liberdades individuais, há o crescimento de instrumentos de controle repressivo. No campo da segurança pública, essa perspectiva se converte em propostas de controles sociais mais rígidos e, como consequência, políticas penais mais severas. Atualmente, verifica-se o fortalecimento do "Estado Penitenciário", ou seja, formam-se instituições de policiamento e controle por meio das quais o Estado procura se contrapor às desestabilizações sociais e econômicas causadas pelos regimes neoliberais (Bauman, I999; Wacquant, I999). 
A literatura internacional que analisa a questão prisional (Bauman, I999; Wacquant, I999; Garland, 200I; Christie, 2003) constata que atualmente o encarceramento em massa é produto do parâmetro de que os riscos devem ser reduzidos, as políticas de prevenção ao crime devem ser amplas e que os criminosos devem ser severamente punidos e controlados. O penal welfarism, desenvolvido desde a década de I950, é substituído pela percepção de que os criminosos não são de responsabilidade social e que eles se tornaram o que são por causa estritamente das suas escolhas individuais.

As taxas de aprisionamento subiram de maneira vertiginosa. Contudo, a criminologia comparada confirma que não existe, em nenhum sistema penitenciário do mundo, a correlação entre a taxa de encarceramento e o nível de criminalidade (Christie, 2003). A prisão só penaliza uma ínfima parcela da criminalidade, e não está apta a absorver a pequena e média delinquência (Wacquant, 2004). Apesar deste fenômeno, em um período de quinze anos (1988-2003), a população encarcerada no Brasil cresceu cerca de 4I0\% (Adorno, 2006). À medida que aumentam os níveis de encarceramento, cresce o problema da superlotação nas penitenciárias; no caso brasileiro, há um déficit crônico de vagas no sistema prisional. Apesar de o governo federal ter liberado recursos, em meados da década de I990, para a criação de 35 mil vagas no sistema penitenciário do país, o problema da superlotação persistiu (Salla, 2003). Presos que já foram condenados cumprem suas penas em delegacias de polícia, junto com presos provisórios. Em contrapartida, no Brasil, os presos que adquiriram o direito de cumprir suas sanções em regime semiaberto não conseguem vagas no sistema penitenciário para o devido cumprimento deste estágio de pena.

Ainda que a população carcerária tenha crescido, , não se observa a melhoria nas condições de encarceramento. Para agravar o quadro, soma-se a isto a pouca capacidade de mobilização de recursos econômicos para o sistema penitenciário e parca solidez em sua organização democrática, o que impede o respeito aos direitos humanos da população carcerária. Portanto, além da escassez de recursos financeiros destinados ao sistema prisional, a democracia é um valor ainda em processo de consolidação (Salla \& Ballesteros, 2008).

Outro problema de funcionamento do Sistema de Justiça Criminal que piora este cenário é a não execução dos mandados de prisão. De acordo com o Ministério da Justiça (2000), até o ano 2000 acumularam-se $300 \mathrm{mil} \mathrm{man-}$ dados de prisão a serem executados. A execução destes provocaria forte pressão sobre o sistema penitenciário brasileiro, cujas vagas seriam insuficientes para absorver todas as pessoas condenadas pelo Sistema de Justiça Criminal.

No Brasil, foram adotadas políticas penais mais severas para a organização e o funcionamento do aparato repressivo. As prisões passaram a adotar regimes disciplinares mais duros, que vão de encontro ao paradigma 
predominante no sistema penal de reinserção social dos presos. Conforme Wacquant (2004), a missão de "reinserção" ficou reduzida a mero slogan, vazio e cruel.

A Anistia Internacional (2008) relatou que os maus-tratos e as precárias condições sanitárias continuam a marcar o sistema penitenciário nacional: formam os cenários das prisões: celas muito pequenas, construções mal conservadas, dependências sem iluminação e ventilação, áreas semidestruídas e sujas. Acresce que a assistência jurídica e de saúde aos presos são deficientes. As mulheres e os deficientes mentais são os mais afetados pelas carências do sistema prisional, pela precariedade da estrutura das prisões e de atendimento às suas necessidades específicas. Na maior parte das prisões brasileiras, os serviços internos ao cárcere são alvos de críticas dos detentos pela falta de profissionais habilitados para o exercício de determinadas funções. Em contrapartida, as condições de trabalho no sistema penitenciário são ruins, visto que as estruturas física e administrativa dos presídios são problemáticas, os salários são baixos e altos níveis de corrupção são observados no setor administrativo dos sistemas penitenciários estaduais.

Durante a década de 1990 aumentou de forma acentuada a atuação de grupos criminosos dentro e fora das prisões. O crescimento das taxas de violência no país é fruto, em grande medida, da emergência e da disseminação do tráfico de drogas, fenômeno intensificado nos anos I980 (Adorno, 2006). A ação desses grupos eleva os níveis de tensão nas prisões, ocasionando o aumento de rebeliões, bem como o de mortes de detentos provocadas por conflitos entre os próprios presos.

Segundo Sykes (I999), os internos de unidades prisionais desenvolvem organizações próprias que formam uma espécie de "sociedade dos cativos". Esse tipo de sociedade articula papéis distintos - "políticos", "agressores", "comerciantes" etc. - que não só orientam os comportamentos individuais, como também os canalizam com vistas à manutenção de compromissos coletivos dentro das penitenciárias. Formam-se códigos de conduta cuja função é prescrever o recurso às "autoridades" informais para a resolução dos conflitos entre os presos, institucionalizando o uso da força e da violência entre eles.

Essa "sociedade dentro da sociedade" é gerada a partir do isolamento da massa carcerária e se torna propícia ao desenvolvimento de processos de conversão dos internos a uma perspectiva criminosa (Paixão, I987). Os códigos e valores da "sociedade dos cativos" devem ser incorporados na identidade de todos os presos. Para Coelho (I987), forma-se um processo de transformação comportamental entre os detentos, que "cria uma segunda prisão": o interno se torna cativo da "sociedade dos cativos". Os padrões de conduta formulados pelos presos incidem de forma mais direta no cotidiano das prisões do que as determinações da administração penitenciária. Ramalho (I983) aponta que as leis da "massa" disputam com as leis oficiais. 
A "massa" implica um "proceder" que confronta, em muitos momentos, as regras da cadeia com as leis da justiça penal brasileira.

Nota-se que todas essas discussões que envolvem o ambiente prisional pairam, de forma geral, sobre os presos e a administração penitenciária. Os familiares de detentos raramente tornam-se focos de estudo e reflexão, até mesmo porque, tal como relatado acima, as condições prisionais brasileiras não são ideais e, portanto, os estudos e as políticas que envolvem o cárcere se voltam quase sempre ao preso e à administração penitenciária.

Entretanto, o encarceramento impacta em muito a vida do familiar do preso: deterioração da situação financeira, desagregação das relações de amizade e de vizinhança, enfraquecimento dos vínculos afetivos, distúrbios na escolaridade dos filhos, entre outras formas, recaem como um fardo aos familiares (Wacquant, 2004). Adicionalmente, torna-se importante analisar este grupo de pessoas, entre outras razões porque exercem articulações significativas entre o mundo prisional e a vida além-muros. Os familiares de presos constituem uma mediação que permite superar a distância entre o cárcere e o mundo exterior; impossibilitados de trazerem os internos para casa, os familiares tentam levar a casa para dentro dos muros da penitenciária mediante a transferência de atividades íntimas. Nesse sentido, a instalação correcional se transforma em um "satélite doméstico" (Comfort, 2004), por abrigar refeições "em família" e encontros íntimos entre os presos e suas companheiras.

O tema específico deste artigo diz respeito aos produtos trazidos pelas mulheres de presos nos dias de visita aos presídios da cidade do Rio de Janeiro, enfocando, sobretudo, os alimentos levados por elas às penitenciárias. Tanto as famílias quanto os presos denominam esses produtos de "sucatas". Minha análise se fundamenta, particularmente, na perspectiva da antropologia e sociologia das emoções, focalizando três sentimentos que pautam as práticas e narrativas das mulheres de presos sobre o tema: amor, fidelidade e compaixão.

O amor é recorrentemente citado pelas mulheres, sendo basicamente consagrado como o sentimento central que as move às visitas às unidades prisionais (ver Duarte, 2013). Já a fidelidade se constitui como a emoção que garante a manutenção da relação entre a mulher e o companheiro preso. O amor, por si, só não é suficiente para promover a manutenção da relação ao longo do tempo. Por fim, a compaixão está, em boa parte, relacionada ao contexto no qual os internos estão submetidos. Como as condições prisionais são, em muitas circunstâncias, limites, as mulheres se compadecem da dor do preso e, por isto, sentem-se motivadas a se dedicarem a eles.

Pela perspectiva do senso comum das sociedades modernas, as emoções são analisadas como parte da singularidade psicológica do sujeito, sendo, portanto, alheias a elementos da natureza sociocultural. Assim, elas são pensadas como fruto do íntimo de cada indivíduo e têm raízes particulares, 
de maneira que a sociedade e a cultura não agem sobre elas. Contudo, um dos exercícios propostos neste artigo é desconstruir tal visão da emoção e analisá-la segundo uma abordagem socioantropológica (Rezende \& Coelho, 20I0), segundo a qual os sentimentos podem ser percebidos como práticas sociais, estruturados pelas formas de compreensão e concepção do corpo, do afeto e da pessoa. ${ }^{I}$

Para fins deste estudo, considero como mulheres de presos as cônjuges ou companheiras em união estável com eles. Cumpre ressaltar, ainda, que no sistema penitenciário estadual existem três tipos de visitação: a comum, que se dá nos pátios das unidades prisionais; as íntimas, realizadas em ambientes reservados da prisão, destinados à prática sexual; e as extraordinárias, que ocorrem em ocasiões excepcionais, com a anuência da direção da unidade prisional.

O texto se estrutura em quatro seções: a primeira corresponde aos aspectos metodológicos do trabalho; a segunda diz respeito à discussão teórica sobre o tema; a terceira parte expõe as narrativas das mulheres de presos acerca dos alimentos levados nos dias de visitação; por fim, a última seção trata das considerações finais em relação aos principais resultados encontrados neste estudo.

\section{ASPECTOS METODOLÓGICOS}

O trabalho de pesquisa foi iniciado por meio do contato com as mulheres de presos que participaram de uma Oficina de Direitos Humanos desenvolvida na cidade do Rio de Janeiro, voltada para os familiares de presos. Esse projeto, realizado por três organizações da sociedade civil, se deu por meio de reuniões caracterizadas por dinâmicas de grupos com vistas a discutir temáticas relacionadas à Segurança Pública, ao Sistema Penitenciário e à atuação dos órgãos do Sistema de Justiça Criminal. O método de pesquisa desenvolvido para acompanhamento desse projeto foi o da observação, de forma que assisti às reuniões e aos grupos de discussões estabelecidos nos encontros. Além disso, realizei entrevistas semiestruturadas com as mulheres de presos participantes desse projeto.

Caso a minha análise se restringisse às mulheres da Oficina de Direitos Humanos, os meus resultados poderiam ficar enviesados, já que o perfil dos participantes dos encontros era bastante específico. Ou seja, eram pessoas, de alguma maneira, com inserção em assuntos voltados à militância em Direitos Humanos. Então, para além do contato com as mulheres de presos da Oficina, criei, por intermédio de outras fontes, relações com algumas pessoas que tinham membros da família cumprindo pena em presídios do Rio de Janeiro. Faço parte de pesquisas sobre Sistema Penitenciário, Segu- 
rança Pública, Sistema de Justiça Criminal e Violência Urbana, o que me permite ter acesso a outras mulheres de presos fora da Oficina. Nessa etapa da pesquisa, fiz contato e entrevistei uma mulher de preso, que me indicou outra, que, por sua vez, me orientou a conversar com uma terceira pessoa.

Também procurei me relacionar com as mulheres de presos que, nos dias de visita, formam as filas na porta central de um Complexo Penitenciário da cidade do Rio de Janeiro especificamente em frente à entrada principal do Complexo de Gericinó, situado na Zona Oeste da cidade. Gericinó é composto por I2 penitenciárias, dois presídios, dois Institutos Penais, três cadeias, três hospitais, um sanatório penal e uma unidade materno-infantil. Portanto, por Gericinó abranger um grande número de instituições carcerárias, pude ter uma visão geral da dinâmica das filas de mulheres de presos formadas em dias de visitação ao local.

Durante as entrevistas com as mulheres, buscava focar alguns aspectos considerados centrais para a minha pesquisa, como a trajetória delas, como conheceram seus companheiros, qual a percepção que tinham sobre o sistema penitenciário do Rio de Janeiro, qual foi o impacto do cárcere na relação afetiva estabelecida com o parceiro, como se dava a rotina de visitas às unidades prisionais, quais os efeitos das regras da administração penitenciária e dos próprios presos na relação amorosa e, por fim, quais os sentimentos que pautavam tal relação.

Em geral, não encontrei dificuldades em ter acesso aos companheiros e cônjuges de presos. A maioria desses visitantes é do sexo feminino, então, o fato de eu ser mulher me garantiu uma boa abertura no campo, pois muitas dessas pessoas pensavam que eu também iria visitar o meu marido preso. Algumas puxavam assunto comigo espontaneamente, indagando qual unidade eu visitava. Então, explicava que não tinha um companheiro preso, mas que realizava um estudo sobre relações familiares no sistema prisional do Rio de Janeiro. Após essa apresentação preliminar, não encontrava entraves para manter a conversa, pois as mulheres se sentiam dispostas em expor os assuntos relacionados ao sistema penitenciário estadual e à sua dinâmica de visitas.

Entrei em contato com mulheres que mantinham relações afetivas duradouras com os companheiros presos, ou seja, não eram relações de poucos meses. Em todos os casos, as mulheres conheceram seus companheiros fora do cárcere, apresentando uma experiência de convivência com o parceiro enquanto eles se encontravam em liberdade. E o critério de seleção dos entrevistados foi o fato de a mulher ter um parceiro (marido ou companheiro) que cumpria pena no momento da pesquisa.

Adicionalmente, ressalto que as mulheres com quem mantive contato durante o trabalho de campo apresentavam as características gerais dos visitantes do sistema prisional do Rio de Janeiro: a maioria delas era de classe 
baixa, moradora de espaços populares e tinham parca escolaridade. Para se sustentarem, muitas dependiam de seus companheiros, bem como participavam de projetos de transferência de renda, como o Bolsa Família. Boa parte delas tinha entre 20 e 40 anos, possuía filhos com os companheiros presos, alguns dos quais concebidos durante as visitas íntimas realizadas nas unidades prisionais.

\section{SENTIMENTOS NO CÁRCERE}

Por que as mulheres de presos dedicam parte de suas rotinas às visitas em unidades prisionais? Quais sentimentos estão em jogo na vida desses atores, especificamente, nestes dias? Fazendo uma análise das falas e práticas das mulheres de presos com quem tive contato tornou-se possível notar três sentimentos que elas mantinham em relação ao seu companheiro preso: amor, fidelidade e compaixão.

Cronologicamente, o ser amado precisa, antes de tudo, existir e ser conhecido. Para Simmel (2006), a partir de então, não há uma mudança es pecífica no indivíduo que será amado, mas, sim, o ser que o ama passa a vê-lo de maneira distinta. O indivíduo amado é um produto original e unitário que não existia antes de haver o amor. A expressão "meu amor" faz jus a essa ideia, já que representa a produção desenvolvida pelo ser que ama em relação ao ser amado. As pessoas amadas são inseridas em uma categoria totalmente nova e diferente de uma situação em que há ausência de amor. "O objeto do amor não existe antes do amor, mas apenas por intermédio dele" (Simmel, 2006: I25). O amor, portanto, forma seu objeto: enquanto objeto do amor, a pessoa amada é sempre criação do amor.

O amor é o movimento que transporta um sujeito em direção a outro (Simmel, 2006). E o puro conceito do amor, o movimento que traz um sujeito ao outro, destacado da vida da espécie e que permanece como um sentimento essencialmente individual, situado inteiramente dentro do sujeito, é raro de ser visto. Simmel (2006) o chama de amor absoluto, cujo fundamento são duas bases de ação que se tornam expressões de um mesmo comportamento: a) desconexão em relação a tudo que depende da espécie; b) exclusão a priori de toda a substitutibilidade individual. É a priori porque o amor absoluto não pode ser tratado como outro tipo de sentimento após a escolha ter sido feita e a relação se ter reduzido a um único indivíduo.

Parece inútil a tentativa de considerar o amor como um produto secundário, no sentido de que seria gerado por fatores psíquicos primários. Para Simmel (2006), tal sentimento está em um nível demasiadamente elevado para ser comparado às atividades fisiológicas, como respiração, alimentação e instinto sexual. De fato, o amor pode ser classificado como um sentimento 
de primeira ordem, ou seja, uma emoção que abre espaço para o estabelecimento de outros sentimentos diferentes de si mesmo. Por outro lado, tendo como base essa percepção, a fidelidade torna-se importante como uma forma sociológica de segunda ordem, ou seja, como um instrumento de relações já estabelecidas por outros sentimentos, como o amor, por exemplo.

A fidelidade pode ser concebida como um elemento que assegura a manutenção de uma primeira relação, de um sentimento inicial, ainda que existam outras forças em atuação. Assim, a fidelidade torna-se a "inércia da alma" (Simmel, 2004: 32). Tal sentimento mantém a alma em um caminho desenhado por um primeiro sentimento, mesmo após passada a ocasião em que tal sentimento inicial foi traçado. Sem essa inércia das interações existentes, a sociedade como um todo poderia entrar constantemente em colapso ou sofrer transformações de maneiras inimagináveis. Para Simmel (2004), a fidelidade é um de vários modos de conduta necessários nas interações dos indivíduos, ${ }^{2}$ não importando o quão diferente estes são, sociológica e materialmente.

Simmel (2004) não se preocupa em conceituar a fidelidade relacionando-a especificamente ao amor ou, ainda, a outro sentimento. Este é, ele mesmo, um estado psíquico singular que, como já dito, é direcionado para assegurar a continuidade da relação em si, independentemente de qualquer elemento afetivo particular ou volitivo que sustenta o seu conteúdo. Esse estado psíquico do indivíduo é uma das condições a priori da sociedade, sem a qual esta não seria possível, apesar de haver níveis distintos desses estados psíquicos.

A fidelidade é um sentimento particular que não está direcionado para a possessão do outro; ele visa criar laços estáveis entre os indivíduos. Contrariamente a outros afetos, como o amor, ela não é pré-sociológica. A fidelidade atravessa a relação a partir do momento em que esta nasce e, como ferramenta de autopreservação interna, faz com que os indivíduos se mantenham fortemente ligados entre si. Essa característica específica está conectada com o fato de que, mais do que qualquer outro sentimento, a fidelidade é suscetível a intenções morais. Ou seja, a infidelidade é passível de sofrer severas reprovações, significando, em alguns contextos, ausência de amor ou responsabilidade social.

Aos olhos de algumas mulheres de presos e dos detentos, interromper a visitação às unidades prisionais poderia ser considerado como um sinal de infidelidade, ou, ainda, como a ausência de amor por parte da companheira. Mesmo que temporariamente, enquanto durar o período de encarceramento, os laços familiares e domésticos podem ser rompidos no caso de o familiar deixar de encontrar o companheiro na prisão. No entanto, o esforço contrário, ou seja, o empenho em manter as visitas pode evidenciar o amor, a fidelidade e, portanto, a garantia da manutenção das relações conjugais durante a fase do encarceramento. Para além de ir à unidade prisional, tais sentimentos fazem com que a mulher de preso praticamente cumpra a pena de prisão 
junto com o membro da família encarcerado, já que, além de passar parte de sua semana na prisão nos dias de visita, ela se submete ao controle e escrutínio do cárcere, sofrendo revistas íntimas e outros tipos de controle da administração penitenciária (ver Duarte, 2010; ARP, 2007).

Outro sentimento que marca as práticas e narrativas das mulheres de presos é o de compaixão. Em linhas gerais, a mulher se compadece da dor do preso e, por isso, dedica-se a ele. Esse sofrimento cresce na medida em que a mulher toma conhecimento do tratamento dispensado ao interno, fruto das privações sentidas durante a sanção de restrição da liberdade, materializando-se, entre outras questões, na carência material, precariedade física do cárcere, dificuldade de acesso à Justiça e a outros serviços.

Assim como ocorre com a fidelidade, o sentimento de compaixão pode ser entendido como elemento crucial para a formação da sociedade. A compaixão estabelece e reforça relações, bem como conecta as pessoas emocionalmente. Ela constrói a ordem social, dando substância às interações. Em outras palavras, a compaixão se constitui como a "cola da sociedade" (Clarck, I998: 5). Dar ou não compaixão e recebê-la ou não pode mudar o curso da interação e da relação. A compaixão, então, se estabelece como a transação cuja função é ajudar a criar e recriar a estrutura do meio social, já que conecta o afortunado ao não afortunado, permite uma quebra, mesmo que temporária, em relação aos problemas da vida e, ainda, cria um ciclo mais amplo para debates acerca de moralidade e justiça social. Permite que um indivíduo olhe o outro e, a partir de então, fica definida uma espécie de ponte entre os dois. Cria-se, por conseguinte, uma linha entre o "nós" e o "eles", estabelecendo relações de alteridade entre indivíduos.

A compaixão cria laços de obrigação e reciprocidade. De forma geral, a pessoa que sente compaixão e ajuda o outro pede algum tipo de retribuição, ainda que seja em forma de sentimentos (gratidão, amor ou uma compaixão futura). Nesse contexto, a compaixão torna-se parte de uma "economia socioemocional" (Clarck, I998: 20), conectando membros de grupos, comunidades e sociedades em redes de sentimentos e interações recíprocas.

Nesses termos, interpreto os sentimentos analisados nesta seção, o amor, a fidelidade e a compaixão, como espécies de dádivas (Mauss, 1974), que criam relações de reciprocidade e proximidade, mas não de forma livre nem desinteressada. São como contraprestações, tendo em vista o estabelecimento e a manutenção de conexões que, em muitos casos, não podem ser recusadas. A dádiva aqui é, simultaneamente, o que deve ser feito, o que deve ser recebido e o que, no entanto, é perigoso tomar, pois precisa ser retribuída. Isto porque a própria coisa dada estabelece um vínculo bilateral e irrevogável. E a obrigação criada se exprime de forma mítica, imaginária, simbólica e coletiva, sendo que as coisas jamais se separam completamente de quem as troca (Mauss, I974). 
Conforme será descrito na próxima seção, as mulheres levam, nos dias de visita, os alimentos aos presos. À primeira vista seria possível pensar que se estabelece a seguinte relação de troca dentro do cárcere: a mulher leva a comida nos dias de visita e os presos, por sua vez, retribuem com sentimentos de proximidade, intimidade e afeição. Estruturar-se-ia, pois, a relação de dar (bens materiais: mulher ao preso), receber (emoção: preso à mulher) e retribuir (mais bens materiais: mulher ao preso). No entanto, argumento que tal relação de troca se enraíza em bases mais profundas que as fundamentadas em um mero intercâmbio de bens materiais por parte da mulher. Dentre os diversos sentimentos possíveis em relações domésticas e familiares, as contrapartidas das companheiras dos presos são: o amor, a fidelidade e a compaixão. Todos esses sentimentos se encontram materializados nas coisas repassadas aos detentos durante a visita. Nesse sentido, a "sucata" levada pela mulher ao interno torna-se a concretização do afeto. Entre outras coisas, tais bens permeiam a relação homem e mulher estabelecida no cárcere.

\section{"SUCATA" PARA OS PRESOS}

Antes de discutir os alimentos trazidos pelas mulheres nos dias de visita, mostro abaixo um trecho de um fórum da Internet cujo conteúdo abrange a discussão proposta nesse texto. ${ }^{3}$

O que fazer quando alguem que vc gosta foi preso? me ajudem vcs ia (sic) visita-lo?

Analize (sic) bem a situação em que vc. se encontra, O tempo que ele vai passar na cadeia e a gravidade do delito Vc. se garante sozinha ou precisa de um companheiro ao seu lado ? Como vc lida com a solidão, com a privação sexual ,com a perspectiva constante de humilhações de todo tipo que vc terá que enfrentar, ate para visita-lo. Com o estigma social de ser mulher de preso? Tudo isso e muito +++ sera parte da sua vida. Se vc. Apenas gosta",salte fora, a barra e muito pesada... Se vc. AMA, enfrenta tudo e segue em frente. Bjs Ti !

[...] Claro q toda luta tem batalhas a ser vencidas, bate a solidão, carência, pensamentos negativos, mais (sic) o amor fala mais alto, e quando vc menos esperar tudo isso passa $[\ldots]$

Estas falas são bastante reveladoras em relação às consequências que o sistema penitenciário pode trazer às mulheres de presos. Apenas o questionamento mostrado acima já explicita a tensão que o cárcere pode trazer à vida do parente de preso. Caso não tivesse dúvidas em visitar seu companheiro encarcerado, a pessoa não precisaria expor seu problema aos participantes de um grupo de discussão: ou teria a certeza de ir visitá-lo, ou descartaria esta possibilidade. No entanto, a mulher busca avaliar, a partir de outros pontos de vista, se compensa abrir espaço em sua rotina para os dias de visitação à penitenciária. Será que vale a pena visitar o companheiro na cadeia? 
As respostas acima não foram as únicas fornecidas a este questionamento. Busquei selecionar, dentre todas as opiniões dos participantes do grupo de discussão, aquelas mais relevantes para este trabalho. Tais falas são favoráveis à visitação, sendo necessário, no entanto, levar em consideração a solidão, a carência, a privação, a humilhação e o estigma de ser mulher de preso. Vários sentimentos estão em jogo neste processo, sendo que o "amor" se torna crucial para avaliar a ida ou não ao cárcere. Há, portanto, dois níveis de sentimentos: o "gostar", relativamente depreciado, já que estabelece uma relação mais fraca e, portanto, pouco estável entre o casal; e o "amar", que embasa uma relação duradoura, forte e, por conseguinte, essencial para a manutenção do vínculo familiar durante o cumprimento da pena. O mero "gostar" não é suficiente, "não compensa", segundo uma perspectiva utilitária, frente aos problemas enfrentados pelos visitantes do sistema penal. Contudo, o "amar" cria laços, fortifica as relações e, portanto, une as pessoas, ainda que em um contexto como o prisional. "O meu (marido) está preso duas vezes, uma na modulada de Montenegro e outra no meu coração. Te amo, amor". ${ }^{4}$

Torna-se interessante analisar que boa parte das consequências consideradas "comuns" às pessoas cumprindo pena, como o confinamento que traz a solidão e a privação em relação ao lado de fora do presídio, repercute de alguma forma na vida de mulheres de presos. Uma das funções do isolamento imposta pela prisão é retirar os detentos de seus mundos socialmente significativos (Paixão, I987). No entanto, essa consequência trazida pelo sistema penal não apenas repercute na vida do condenado, como também pode afetar sua companheira. Tal como o preso, a mulher sofre os sentimentos de "privação" e de "solidão" que permeiam as rotinas dos presídios. Tudo isso gerado pela tentativa de a mulher trazer para dentro dos muros da prisão algumas das relações significativas do preso estabelecidas fora do contexto prisional. Ou seja, esses sentimentos estão relacionados à busca da mulher em recriar o ambiente doméstico, bem como em trazer sentimentos da esfera íntima e privada ao cárcere. ${ }^{5}$

Por outro lado, ouvi relatos de que ser "mulher de preso" representa, para algumas pessoas, uma espécie de "estilo de vida", ou seja, "uma diversão". As mulheres fazem amizades com outras visitantes nas portas das prisões, marcam de se encontrar antes das visitas, conversam e trocam experiências. Em suma, ao mesmo tempo em que pode gerar consequências negativas à vida de algumas companheiras de presos, o sistema penitenciário pode acarretar efeitos benéficos, como agregar pessoas, produzir solidariedade, em um sentido sociológico. Essa experiência mais positiva com o cárcere está diretamente relacionada não só com as redes formadas entre familiares de presos, mas também com o tipo de relação estabelecido com a administração penitenciária. 
Mas a gente não, quando já ia um grupo de mulheres que a gente fazia amizade lá, a gente ia e ficava, às vezes, a noite toda acordada, conversando. Pra algumas ali, era um estilo de vida, era uma diversão [...]. Pra outras, não. Pra outras era muito sofrimento. E, dependendo de cada presídio, é muita humilhação (Entrevista com mulher de preso).

A maioria das mulheres com quem mantive contato ressaltou o momento de preparação para os dias de visita como uma ocasião importante em suas rotinas semanais. Adicionalmente, em minha pesquisa tornou-se bastante comum ver um grande número de mulheres chegando ao Complexo de Gericinó, de manhã cedo, se não de madrugada, carregando bolsas de plástico abarrotadas de comida, doces, cigarros e refrigerantes.

Nos dias anteriores à visita, a mulher dispensa boa parte do seu tempo a preparar os alimentos que serão levados às unidades prisionais. A esposa de um interno informou que praticamente não dormia nas noites anteriores às visitas porque passava grande parte da madrugada cozinhando. Os preparativos para a visita começavam alguns dias antes do encontro, pois havia a necessidade de ela ir ao supermercado comprar os ingredientes para preparar a comida. A compra de determinados alimentos chegava a gerar rixas familiares, porque certos parentes, principalmente os de baixa renda, comprometiam a qualidade ou a quantidade da alimentação da família para garantir a satisfação do parente preso.

Todo esse esforço em comprar, preparar e levar o alimento à prisão se dá, em parte, pelo fato de a comida ser um veículo para a criação de vínculos de intimidade entre a mulher e seu companheiro preso. Para além disso, os sentimentos de amor, fidelidade e compaixão se materializam nas comidas e são trocados nos dias de visitação aos detentos. A comida se torna, pois, um elo condutor na relação entre a mulher e o preso, já que funciona como uma espécie de ponte entre o mundo material e sentimental familiar. De fato, há pessoas que levam os alimentos nos dias de visita sem se preocupar em transmitir os sentimentos em questão, já que objetivam garantir, sobretudo, a saciedade física do preso. Já nessas situações a comida apresenta um enorme valor no cárcere, pois garante um bem-estar físico ao preso. No entanto, para todas as mulheres entrevistadas, a atitude de preparar e levar a comida tinha um significado adicional justamente pelo fato de o alimento adquirir uma carga emocional diferente daquela que teria se tivesse sido produzido para ser consumido em uma refeição comum.

Comer é uma atividade central da vida humana, não só por ser fisiologicamente necessária, mas porque carrega em si uma forte marca social e cultural. Segundo Mintz (200I), o ato de ingerir o alimento denota o consumo não só de substâncias nutritivas, mas também de uma carga moral que expressa, entre outras situações, o contexto em que a comida foi produzida e o significado social e individual que ela possui. Então, no momento em que 
a comida literalmente "entra" no preso, ele não apenas assimila o alimento, mas também absorve a carga emocional com que foi produzido. O entendimento de que durante a reclusão os homens recebem suprimentos inadequados de comida leva as mulheres a compensar essa deficiência. Então, levar a "sucata" nos dias de visita é muito importante para os presos, porque eles se queixam de que a comida oferecida no presídio é de baixa qualidade. Algumas unidades possuem cozinhas onde os internos preparam os alimentos de todos os detentos. Em outras penitenciárias a comida é levada por empresas terceirizadas eservida em "quentinhas". Quando a comida é preparada na unidade prisional, os internos não reclamam muito do alimento servido. Entretanto, quando a comida é trazida em "quentinhas", é bastante comum escutar clamores a respeito do alimento, que, na maioria das vezes, chega azedo aos presídios.

A comida de lá, eles falam: "o preso ta comendo bem". Mentira, a comida é azeda. Muitas das vezes eles tinham que comer comida azeda. Eu já vi chegando aqueles caminhões e baús fechado, sem saber qual percurso aquele caminhão e baú fez pra chegar até ali. Aquela comida... (Entrevista com mulher de preso).

A mulher se compadece da situação do preso e, com isso, tenta reverter as condições precárias das unidades prisionais através de demonstração de amor e fidelidade, materializadas em comidas de origem caseira. Tendo isso em vista, chama a atenção o fato de a comida do preso levada pela mulher ser denominada de "sucata". Literalmente, esse termo diz respeito a objetos que podem ser descartados, eliminados, por deixarem de ter a serventia para o qual foi projetado. No entanto, de forma alguma a comida preparada pelas companheiras dos presos poderia ser analisada como um bem eliminável, já que ela apresenta múltiplas funções (alimentar; demons trar zelo, afeição, carinho; firmar relações) essenciais ao convívio familiar no cárcere.

Não é qualquer tipo de comida que pode ser levado durante as visitas. ${ }^{6}$ Todos os objetos trazidos à prisão sofrem intensa fiscalização por parte dos agentes penitenciários. Em vista disso, muitas mulheres ficam frustradas em dispensar muito tempo e dinheiro no preparo de alguns alimentos que são barrados na entrada das unidades prisionais.

A comida só entrava em dia festivo: no dia das mães, na páscoa. Comida mesmo de casa: arroz, feijão, frango... e nem era todo tipo de comida. Porque tinha comida recheada, como era o empadão que não podia entrar. Uma lasanha não podia entrar, porque eles achavam que tava levando droga ali dentro. O bolo tinha que ser todo cortado, fatiado. Uma das vezes, quando era bolo recheado, eles não deixavam entrar. Já aconteceu de eu voltar com bolo recheado devido eu não cortar, porque eles acharam que no meio do recheio tinha alguma coisa. É um absurdo. E é até hoje, um absurdo (Entrevista com mulher de preso). 
Pode-se depreender uma tentativa de recriar e importar o lar para dentro da unidade prisional no momento em que o familiar leva os alimentos preparados no ambiente doméstico. No entanto, quando a "sucata" é proibida de entrar nas unidades prisionais, essa expectativa de reconstrução do ambiente doméstico dentro do cárcere se frustra. Também, todo o sentimento devotado na preparação da comida e toda a emoção que esse alimento materializa é posto abaixo pela direção do presídio.

De fato, constrói-se uma relação de força entre a família e a administração penitenciária. De um lado, as mulheres querem reafirmar os laços domésticos no contexto prisional, transpondo para dentro dos muros do cárcere valores e sentimentos típicos da vida familiar, privada. Por outro lado, a administração penitenciária procura reforçar o controle institucional não só sobre os presos, mas, nessas situações, também sobre a família. Fica estabelecida, pois, uma "queda de braço" entre ambos os atores, na qual o visitante se frustra ao ver o alimento preparado literalmente destroçado e, com isso, todo o esforço na preparação da "sucata" ser pulverizado. Mas, também, a administração penitenciária precisa, a todo o momento, exercer seu papel de controle, com vistas a impedir que os valores trazidos do "lado de fora", articulados pelas companheiras dos presos, impeçam ou prejudiquem o domínio institucional sobre o interno.

Uma entrevistada apontou que o ambiente dos presídios é "horrível". Todo o controle voltado ao familiar causa um "trauma emocional" muito grande. Segundo essa perspectiva, é necessária muita "resistência" para frequentar o sistema penitenciário do Rio de Janeiro. Remetendo às falas do início desta seção, ouvi a seguinte narrativa: "Ali [no presídio] só vai quem ama. Senão, você não volta mais. Não volta mais”. Assim, a demonstração de amor, simbolizada no esforço para a realização da visitação se torna um sentimento "puro" e "verdadeiro". A companheira do preso "aguenta" o sistema prisional pelos sentimentos que permeiam a relação com o parente preso. E, caso tais emoções não fossem "genuínas", a mulher não realizaria as visitas. Ela não "aguentaria", não "suportaria” o contato com o cárcere.

Em suma, torna-se clara a tentativa das mulheres em explicitar enfaticamente o esforço e a devoção por seus companheiros presos. Entre uma gama de outros sentimentos, o amor, a compaixão e a fidelidade consubstanciam as comidas trazidas no dia de visita às unidades prisionais. Todo este complexo emocional empreendido pelas mulheres na realização de tais alimentos é trocado com sentimentos de proximidade, intimidade, afeto etc., por parte dos presos. Assim, a relação afetiva estabelecida não é uma via de mão única, de maneira que a mulher recebe algo em troca, tal como uma dádiva (Mauss, I974).

Algumas mulheres mencionaram o fato de terem sido traídas e até mesmo abandonadas por seus companheiros quando estes se encontravam 
em liberdade. Porém, a prisão os teria levado a reconhecer o esforço de suas companheiras em visitá-los e, por isso, passar a valorizá-las. Algumas ressaltaram que se sentem em parte "aliviadas" com a restrição de liberdade do companheiro, que, por estarem encarcerados, não têm contato com outras mulheres. Parece que o cárcere estabelece uma espécie de "fidelidade forçada" ao homem, mantendo-o exclusivo na relação amorosa. Escutei diversos relatos sobre companheiros que ficaram mais carinhosos, atenciosos e dedicados às companheiras após terem sido presos. Nessa mesma linha, Silvestre (2012) afirma que mulheres de presos ressaltaram uma diferença entre o amor que viviam com seus companheiros presos e suas outras experiências amorosas. Os presos tinham o "melhor amor do mundo" (Silvestre, 2012: 272), sendo mais afetuosos com suas parceiras.

Uma entrevistada mencionou que, ao dar à luz seu filho, ficou cerca de seis meses internada no hospital por complicações na gravidez e no parto. Nesse período, o marido a visitou apenas três vezes e, nesses raros encontros, travava brigas com ela, deixando claro que saía com outras mulheres. Ao ser preso, a mulher decidiu visitá-lo sob as condições de que não poderia mais ser traída e deveria ser valorizada pelo esposo. Desde então, como o companheiro passou a tratá-la muito bem, a mulher ficou satisfeita com a relação. No entanto, ela tinha a preocupação de o marido voltar a ficar displicente ao voltar à condição de liberdade. Da mesma maneira em que acreditava em uma mudança positiva permanente no comportamento do marido sobre o casamento, a mulher tinha receio de que voltasse a ser desvalorizada no momento em que ele ganhasse a liberdade.

Adicionalmente, escutei relatos de que alguns homens não queriam ter filhos com suas companheiras quando se encontravam em liberdade. Contudo, com a prisão, começaram a fazer pedidos insistentes para que as mulheres engravidassem e muitas delas acataram essas solicitações bastante satisfeitas. A percepção de que o nascimento de uma criança deixa a relação mais estável e duradoura é quase dominante. O contato entre a mulher e seu parceiro passa a ser intermediado por uma terceira pessoa, que é dependente, em boa medida, de que tal relação seja perene. Nesse contexto, ao invés de prejudicar a relação, o contato com o cárcere pode reforçá-la, se não reestruturá-la. Godoi (20I I) aponta que, embora seja estigmatizante e segregadora, a prisão não é necessariamente desestruturadora. Em certa medida, ela pode ser reestruturante e produtiva, capaz de criar e reforçar vínculos afetivos, tais como o de um casal.

A princípio, poder-se-ia pensar que as "sucatas" trazidas pelas mulheres de presos nos dias de visita são marginais à vida do cárcere. No entanto, uma 
análise mais densa desses comportamentos a partir de relatos femininos possibilitou compreender, em boa medida, como se estabelecem relações afetivas no cárcere. Ou seja, entre outras questões, quais sentimentos estão em jogo para as companheiras de presos, quais tipos de interações se estabelecem nesse cenário, o que as mulheres dão e recebem quando levam a comida aos seus parceiros.

O amor, a fidelidade e a compaixão são centrais nessas trocas estabelecidas entre as mulheres e os presos, pois aparecem como sentimentos transversais às relações. E, portanto, a comida torna-se uma espécie de corpo físico desse complexo emocional, estando sujeita a uma série de implicações típicas de um contexto estigmatizante, escrutinante e segregado, como o penal. O controle da administração penitenciária, a devoção do familiar para com o preso, a "fidelidade forçada" do detento à sua mulher, enfim, uma série de microrrelações se manifesta através dos alimentos trazidos nos dias de visita.

Portanto, levar "sucata" representa um objetivo muito mais amplo do que saciar uma necessidade física de um interno. Para além disto, a comida trazida pela mulher ao seu companheiro privado de liberdade traduz uma gama emocional e interacional bastante complexa que abrange diversos aspectos centrais da vida prisional e da relação afetiva entre o preso e sua companheira.

Recebido em I6/oI/20I2 | Aprovado em I5/04/20I3

Thais Lemos Duarte é bacharel em Ciências Sociais pela Universidade do Estado do Rio de Janeiro (UERJ) e mestre pelo Programa de Pós-Graduação em Sociologia e Antropologia da Universidade Federal do Rio de Janeiro (PPGSA/UFRJ). Atualmente, faz doutorado pelo Programa de Pós-Graduação em Ciências Sociais da UERJ e é pesquisadora do Laboratório de Análise de Violência desta universidade. Trabalha em pesquisas sobre segurança pública, violência e sistema de justiça criminal. 


\section{NOTAS}

I A antropologia das emoções ganhou força a partir da década de I980, com a publicação do texto de Rosaldo (1984), o qual expõe ser tarefa da antropologia mostrar de que modo a cultura interfere na experiência psicológica do indivíduo (Coelho, 2010).

2 Segundo o autor, a sociedade é formada a partir das relações entre os indivíduos, ou seja, a síntese mental que constitui a sociedade, sua unidade, é produto das próprias atividades individuais. Ela existe onde os homens estão em convivência, em ação conjunta, em relação de circunstâncias com outros homens (Simmel, I977: 16). A sociedade não é estática e acabada, ela é algo que acontece e que está acontecendo (Moraes Filho, I983: 2I), de modo que deixa de ser uma substância, ou qualquer outra coisa concreta, e se torna um acontecimento (Simmel, I983: 84).

3 Disponível em <http://br.answers.yahoo.com/question/in dex?qid=2006I022I44432AAiBCkM>. Acesso em I5 dez. 20 I.

4 Disponível em <http://www.orkut.com.br/Main\#CommMs gs? $\mathrm{cmm}=$ I I $4787727 \& \mathrm{tid}=57$ I I 8809 I I $753385990>$. Acesso em 24 jul. 2012.

5 Goffman (2007) analisa que os internos de instituições totais realizam boa parte de suas atividades diárias em promiscuidade com outros internos. Nas prisões, os banhos, as refeições, as necessidades físicas, os encontros familiares e, em alguns locais, as próprias visitas íntimas, são realizados em contato, se não direto, muito próximo de outros detentos e de membros da administração penitenciária.

6 Nos dias de visitação, cada interno pode receber até duas bolsas de plástico ou de papel, dos tipos das usadas em supermercado, contendo (Art. $\mathrm{I}^{\circ}$ Resolução SEAP $\mathrm{n}^{\circ} 26$, de 7 de julho de 2003): I - frutas diversas, alimentos cozidos, leite em pó acondicionado em embalagem tipo saco, biscoitos, bolos e doces acondicionados em sacos ou vasilhames plásticos transparentes; II - cigarros; III - material de higiene pessoal (escova e pasta de dente, sabonete, papel higiênico, xampu e absorvente higiênico); IV - lençóis e toalhas; V - calçados; VI - peças de vestuário. 


\section{REFERÊNCIAS BIBLIOGRÁFICAS}

Adorno, Sérgio. (2006). Crimen, punición y prisiones en Brasil: un retrato sin retoques. Madri: Quorum.

Anistia Internacional. (2008). Relatório Brasil. Informe 2008. Disponível em <http://brasil.indymedia.org/media/2008/05//420860.pdf>. Acesso em 27 jun. 2010.

Arfuch, Leonor. (20I0). O espaço biográfico: dilemas da subjetividade contemporânea. Rio de Janeiro: Ed. UERJ.

Associação pela Reforma Prisional. (2007). Procedimento de revista dos familiares das pessoas presas no estado do Rio de Janeiro - o caso das visitantes do sexo feminino. Rio de Janeiro: Universidade Candido Mendes.

Bauman, Zygmunt. (I999). Globalização: As consequências humanas. Rio de Janeiro: Zahar.

Clarck, Candance. (1998). Misery and company. Sympathy in everiday life. Chicago/ Londres: University of Chicago Press. Christie, Nils. (2003). L'industrie de la punition. Prison et politique pénale en Occident. Paris: Autrement.

Coelho, Edmundo Campos. (1987). A oficina do diabo: crise e conflito no sistema penitenciário do Rio de Janeiro. Rio de Janeiro: Espaço e Tempo.

Coelho, Maria Claudia. (2010). Narrativas da violência: a dimensão micropolítica das emoções. Mana, I6/2, p. 265-285. Comfort, Megan. (2004). "A casa do papai”: a prisão como satélite doméstico e social. Discursos Sediciosos, I3, p. 77-IOI. Departamento Penitenciário Nacional. (2000). Relatório de Gestão. Exercício 2000. Brasília: Ministério da Justiça.

Duarte, Thais Lemos. (2013). Sentimentos no cárcere: análise das narrativas de mulheres de presos sobre o amor. Revista Brasileira de Sociologia da Emoção, I2/34, p. I9I-2I8. Duarte, Thais Lemos. (2010). Análise dos procedimentos de revistas íntimas realizados no sistema penitenciário do estado do Rio de Janeiro. Revista Sociologia Jurídica, I, p. Io-30. Garland, David. (200I). The culture of control: crime and social order in contemporary society. Chicago: University of Chicago Press.

Goffman, Erving. (2007). Manicômios, prisões e conventos. São Paulo: Perspectiva. 
Marchetti, Anne-Marie. (2004). Empobrecimento carcerário: desigualdade de classe na penitenciária francesa. Discursos Sediciosos, I3, p. 4I-55.

Mauss, Marcel. (1974). Ensaio sobre a Dádiva. In: Sociologia e Antropologia. São Paulo: EPU.

Mirabete, Julio Fabrini. (I99I). Manual de direito penal. 6. ed. São Paulo: Atlas.

Mintz, Sidney W. (200I). Comida e antropologia: uma breve revisão. Revista Brasileira de Ciências Sociais, I6/47, p. 3I-42.

Moraes Filho, Evaristo de (org.). (I983). Sociologia: Simmel. São Paulo: Ática.

Paixão, Antonio Luiz. (1987). Recuperar ou punir? Como o Estado trata o criminoso. São Paulo: Cortez/Autores Associados. Ramalho, José Ricardo. (I983). Mundo do crime a ordem pelo avesso. 2. ed. Rio de Janeiro: Graal.

Resolução SEAP n 26. (2003). Secretaria de Estado de Administração Penitenciária. Rio de Janeiro. o7 de julho de 2003. Disponível em <http://www.rj.gov.br/web/seap/ listaconteudo? search-type=legislacao \& secretaria=/seap $>$. Acesso em I3 dez. 201 I.

Rezende, Claudia Barcellos \& Coelho, Maria Claudia. (20I0). Antropologia das emoções. Rio de Janeiro: Ed. FGV.

Rosalvo, Michelle. (1984). Toward an anthropology of self and feeling. In: Shweder, Richard \& LeVine, Robert (orgs.). Culture theory - essays on mind, self and emotion. Cambridge: Cambridge University Press.

Salla, Fernando Afonso. (2003). Os impasses da democracia brasileira. O balanço de uma década de políticas para prisões no Brasil. Lusotopie, IO, p. 419-435.

Salla, Fernando Afonso \& Ballesteros, Paula Rodriguez. (2008). Democracia, direitos humanos e condições das prisões na América do Sul. Relatório de Pesquisa NEV/USP. São Paulo.

Simmel, Georg. (2006). Filosofia do amor. São Paulo: Martins Fontes.

Simmel, Georg. (2004). Fidelidade e gratidão e outros textos. Lisboa: Relógio D’Água. 
AMOR, FIDELIDADE E COMPAIXÃO: “SUCATA" PARA OS PRESOS

640

Simmel, Georg. (1983). O campo da sociologia. In: Moraes Filho, Evaristo de (org.). Sociologia: Simmel. São Paulo: Ática.

Simmel, Georg. (I977). Sociología: estudos sobre las formas de socialización. Madrid: Alianza Editorial.

Silvestre, Giane. (2012). Dias de visita: uma sociologia da punição e das prisões. São Paulo: Alameda.

Soares, Luiz Eduardo. (2003). Novas políticas de segurança pública. Estudos Avançados, I7, p. 75-96.

Sykes, Gresham M. (I999). The society of captives: a study of a maximum security prison. New Jersey: Princeton University Press.

Wacquant, Loïc. (2004). A aberração carcerária à moda francesa. Dados: Revista de Ciências Sociais, 47/2, p. 215-232. Wacquant, Loïc. (I999). Les prisons de la misère. Paris: Raisons d'Agir. 


\section{Palavras-chave}

Sistema penitenciário; Mulheres de presos; "Sucatas";

Visitas a detentos; Controle penitenciário.

Keywords

Penitentiary system; Prisoners' women; "Scraps";

Visiting prisoners; Penitentiary control.

\section{AMOR, FIDELIDADE E COMPAIXÃO: "SUCATA" PARA OS PRESOS \\ Resumo}

O artigo apresenta um foco que, de forma geral, permanece quase imperceptível à sociedade e ao Sistema de Justiça Criminal como um todo: as mulheres de presos. O tema desse artigo gira em torno dos produtos trazidos pelas mulheres de presos nos dias de visita às unidades prisionais da cidade do Rio de Janeiro - as "sucatas" -, tratando especificamente dos alimentos levados por elas. A análise se pauta, sobretudo, na perspectiva da antropologia e da sociologia das emoções, de modo que dentre os diversos sentimentos possíveis em relações domésticas e familiares, as contrapartidas das companheiras dos presos se tornam no contexto prisional o amor, a fidelidade e a compaixão. Todos esses sentimentos se encontram materializados nas coisas repassadas aos detentos durante a visita. Nesse sentido, as "sucatas" levadas pela mulher ao interno tornam-se a concretização do afeto. Entre outras coisas, tais bens permeiam a relação homem e mulher estabelecida no cárcere.

\section{LOVE, FIDELITY, AND COMPASSION: "SCRAPS" FOR PRISONERS}

\section{Abstract}

The article addresses an object that in general remains almost imperceptible to society and the Criminal Justice System as a whole: prisoners' women. It focuses the products, specifically the food, brought to prisons by the prisoners' women in visiting days in the city of Rio de Janeiro. These are called "scraps" ("sucatas"). The analysis is mainly based on the perspective of anthropology and sociology of emotions. Accordingly, it is argued that among many possible feelings of domestic and familial relationships, the counterpart of the prisoners' partners becomes in the prison context love, fidelity and compassion. In that sense, as materialized feelings, the things that the women take to the interns, the so called "sucatas", can be seen as the concretion of affection, and pervade the relationship between man and woman established in prison. 